\title{
SOBRE LOS DISTRITOS, LAS EXPLOTACIONES Y LA TOPONIMIA CLANICA DE YĀBISA* (EIVISSA)
}

Por ANGEL POVEDA

La fuente fundamental para el estudio de la toponimia árabo-beréber de la isla de Ibiza es el Memoriale Divisionis. He utilizado para este trabajo la excelente transcripción y estudio del investigador ibicenco Joan Marí Cardona publicada por el Institut d'Estudis Eivissencs en el año 1976.

El documento que ha llegado hasta nosotros es una copia en latín conservada en el Archivo Histórico de la Pabordía de Ibiza que, como indica J. Marí, está llena de anomalías e irregularidades ya que el texto original, en principio conservado en el Archivo del Arzobispado de Tarragona y después en el archivo de la Iglesia de lbiza, ha desaparecido. Aunque el documento conservado no lleva ninguna indicación en cuanto a fecha de su escritura, J. Marí considera, por diversas razones que no vienen al caso, que fue redactado poco después de 1235.

Mediante una escritura del 7 de diciembre de 1234 , el rey Jaume I cedió a Guillem de Montgrí, sacristán de Girona y arzobispo electo de Tarragona, los derechos de conquista de la isla de lbiza como feudatario suyo, reservándose el rey el derecho de soberanía. A su vez, G. de Montgrí suscribió un convenio por el cual Pedro, Infante de Portugal y Nunó Sanç, Conde del Rosselló, pasan a ser sus feudatarios, comprometiéndose éstos a colaborar con sus hombres en la conquista de la isla.

En el convenio se especifica que se repartirán por partes iguales el castillo y la ciudad de lbiza, mientras que las tierras de fuera de la ciudad, así como las salinas y Formentera, se repartirán en partes proporcionales al número de soldados que aporten cada uno de los magnates. Una vez llevada a cabo la conquista y en función de lo convenido previamente, dos

* Este trabajo fue presentado en la «Table ronde de toponimie et archéologie d'al-Andalus» celebrada en la Casa de Velázquez, en Madrid, los días 12-14 de diciembre de 1983. 
cuartas partes de las tierras de Ibiza, Formentera y de la sal de las salinas pasaron a dominio de $G$. de Montgrí, siendo el resto repartido en partes iguales entre el Infante de Portugal y Nunó Sanç.

A través del Memoriale Divisionis sabemos que durante la época musulmana, Yäbisa se hallaba dividida en cinco distritos que recibian los nombres de Alhaueth, Xarch, Benizamid, Portumany y Algarb. Para llevar a cabo el reparto de la isla, los cinco distritos musulmanes quedaron reducidos a cuatro, siendo Alhaueth, que era el distrito que formaba el hawz de madina Yābisa dividido en cuatro partes desiguales, las cuales fueron incorporadas a los restantes cuatro distritos. El hecho de que fuera Alhaueth y no otro el distrito repartido, parece indicar la especial importancia de estas tierras, no sólo porque formaban la rodalía de la ciudad y castillo de la isla, sino porque el Pla de la Vila sería algo semejante al Prat de Sant Jordi en Mallorca y las otras fértiles tierras que envuelven, sobre todo por el Este, Nordeste y Norte a la madina Mayürqa. Se trataría, en definitiva, de tierras especialmente codiciadas por su calidad, irrigación y alta productividad.

Para lograr que las cuatro partes fueran semejantes en cuanto a sus dimensiones y calidad de tierras, una pequeña porción de Benizamid fue agregada a Xarch. Un trozo considerable de Portumany fue añadido a Benizamid y otra porción de Algarb pasó a Portumany.

Basándose en los lindes y referencias topográficas que proporciona el Memoriale Divisionis, así como en otros documentos y una minuciosa comprobación sobre el terreno, J. Marí ha podido reconstruir con suficiente fiabilidad los primitivos cinco distritos musulmanes. Esta reconstrucción me ha permitido medir, con un margen de error del $2 \%$ aproximadamente, la superficie correspondiente a los cinco distritos, que ha resultado ser la siguiente: Alhaueth, 67'60 km.2; Algarb, 68'80 km.2; Benizamid, 64'94 km. ${ }^{2}$; Portumany, 164'60 km.2; y Xarch, $185^{\prime} 70 \mathrm{~km} .^{2}$.

Las partes que de Alhaueth se incorporaron a los otros cuatro distritos registran las siguientes dimensiones. Cedido a Algarb, $10^{\prime} 80 \mathrm{~km} .^{2}$; cedido a Portumany, $18^{\prime} 86 \mathrm{~km} .^{2}$, cedido a Benizamid, $11^{\prime} 48 \mathrm{~km} .^{2}$ y cedido a Xarch, 21 '45 km. ${ }^{2}$.

Se ha de tener en cuenta que en la zona de Alhaueth se hallaba enclavada la alquería de Maçana, después denominada de Santa María, que no fue repartida entre los magnates conquistadores ya que fue entregada a la Iglesia de Ibiza junto con ciertas rentas sobre la sal e inmuebles y terrenos en la propia ciudad de Ibiza. Esta gran alquería tenía unas dimensiones de casi $6^{\prime} 5 \mathrm{~km} .^{2}$ y se hallaba situada en el extremo Norte del distrito.

Así mismo, entre los otros cuatro distritos hubo reajustes: $4{ }^{\prime} 74 \mathrm{~km} .^{2}$ del lado Este de Benizamid pasaron a Xarc; $25.5 \mathrm{~km}^{2}$ de la zona NorteNoroeste de Portumany se añadieron a Benizamid y una porción situada al Oeste de Algarb, de $13^{\prime} 3 \mathrm{~km} .^{2}$, pasó a Portumany.

El balance entre los cuatro distritos resultantes después de la nueva 
distribución fue el siguiente: Algarb perdió 2'5 km. ${ }^{2}$, Benizamid ganó 32’3 $\mathrm{km} .{ }^{2}$, Portumany ganó $6{ }^{\prime} 6 \mathrm{~km} .{ }^{2}$ y Xarch ganó también $26^{\prime} 2 \mathrm{~km} .{ }^{2}$.

En el Memoriale Divisionis no hay referencias para concretar si en la época musulmana la isla estaba dividida en aŷzä' o en aqälím ya que en el texto encontramos las palabras terre o partes, siendo este último el término que más veces se repite.

De los cinco nombres de distritos o partes, sólo uno es premusulmán: Portumany, del tipo de los portu o porto de Mallorca, siendo los otros cuatro claramente árabes. Dos de situación geográfica: Algarb $(<a l-g a r b=\mathrm{el}$ occidente) y Xarch o Xarc $(<$ šarq = oriente). Otro en beni: Benizamid $<<B e-$ ni Sãmit $=$ los hijos del pobre). El quinto es denominado Alhaueth, que por tratarse del distrito de la ciudad y, de la misma manera que en Mayürqa. debe ser corrupción de la voz árabe al-hawz (zona de cultivo adyacente a una ciudad y dependiente administrativamente de ella).

Tres de los cuatro distritos resultantes del reparto de la isla por los nuevos pobladores cambiarían su nombre con posterioridad. La excepción fue Portumany, único nombre que con toda seguridad no fue sustituido por resultar familiar a los oídos de los colonizadores.

La relación de explotaciones del Memoriale Divisionis viene distribuida según los cuatro nuevos distritos en que quedó dividida la isla. A diferencia del Llibre del Repartiment de Mallorca, aquí no aparecen las dimensiones de cada una de las explotaciones ni tampoco los nombres de los beneficiarios. Es de suponer que cada uno de los magnates extendería posteriormente los correspondientes documentos de cesión a los explotadores directos de las tierras repartidas o al menos quedarían consignadas las donaciones en registros generales de cuya existencia no tenemos noticia.

Según los quartons o cuatro distritos y los tipos de explotaciones, se puede confeccionar el siguiente cuadro.

CUADRO I

\begin{tabular}{|c|c|c|c|c|c|c|c|}
\hline & n. ${ }^{0}$ explot. & n.o alq. & $\%$ alq. & n.o rah. & $\%$ rah. & otros & $\%$ otros \\
\hline $\begin{array}{l}\text { Algarb. ....... } \\
\text { Benizamid .... } \\
\text { Portumany... } \\
\text { Xarch ....... }\end{array}$ & $\begin{array}{l}22 \\
33 \\
34 \\
32 \\
\end{array}$ & $\begin{array}{l}15 \\
32 \\
26 \\
26\end{array}$ & $\begin{array}{l}68^{\prime} 19 \\
96 ' 97 \\
76 ' 07 \\
81^{\prime} 25 \\
\end{array}$ & $\begin{array}{l}7 \\
1 \\
8 \\
5 \\
\end{array}$ & $\begin{array}{r}311^{\prime} 82 \\
3^{\prime} 03 \\
23^{\prime} 53 \\
15^{\prime} 63 \\
\end{array}$ & $\begin{array}{l}- \\
- \\
-\end{array}$ & $\begin{array}{c}- \\
- \\
- \\
3^{\prime} 12\end{array}$ \\
\hline TOTALES. & 121 & 99 & $81^{\prime} 82$ & 21 & $17 ' 35$ & 1 & $0^{\prime} 83$ \\
\hline
\end{tabular}

El hecho de que el distrito de A/haueth quedara integrado en los otros cuatro de la manera en que se ha indicado anteriormente, impide el que sepamos de cuántas explotaciones y de qué tipo eran las que formaban este distrito. No obstante, he de señalar, aunque no cabe en esta breve exposición explicar su desarrollo, que se puede establecer, a modo de hipótesis, el número y tipo de explotaciones que debieron corresponder a cada una de las zonas administrativas de Yäbisa antes de su distribución por los 
catalanes, mediante cálculos aproximados basados en las dimensiones de las explotaciones mallorquinas, en el porcentaje de tierra cultivable para Mayürqa, en las dimensiones de los primitivos cinco distritos musulmanes y en el número y relación entre alquerías y rahales de Yäbisa.

De la observación del cuadro cabe destacar la abrumadora mayoría de alquerías frente a los rahales. Mientras que en Mayürqa el porcentaje medio de rahales se sitúa en torno al $41^{\prime} 5 \%$, aquí es del $17^{\prime} 35 \%$. Si tenemos en cuenta que las alquerías suelen ser por término medio más grandes que los rahales, alcanzando para Mayũrqa las primeras unas dimensiones medias de 7'37 jovades (83'72 h.) frente a 4'33 jovades $\left(49^{\prime} 02\right.$ h.) los segundos, podemos concluir que las explotaciones de Yäbisa eran generalmente más grandes que las de la isla mayor y que consecuentemente en las alquerías se concentraría la mayor parte del espacio productivo, siendo el rahal un tipo de explotación marginal.

La toponimia en beni o clánica de Yäbisa es particularmente importante dentro del conjunto toponímico que ofrece el Memoriale Divisionis, tal y como se aprecia en e

CUADRO II

\begin{tabular}{|c|c|c|c|c|c|c|}
\hline & n. ${ }^{\circ}$ explot. & $n^{\circ}$ alq. & $\%$ alq. & $n .^{\circ}$ rah. & $\%$ rah. & $\%$ sobre total \\
\hline $\begin{array}{l}\text { Algarb. ........ } \\
\text { Benizamid .... } \\
\text { Portumany.... } \\
\text { Xarch ........ }\end{array}$ & $\begin{array}{r}9 \\
13 \\
19 \\
12 \\
\end{array}$ & $\begin{array}{r}9 \\
13 \\
13 \\
8\end{array}$ & $\begin{array}{c}100^{\prime} 00 \\
100^{\prime} 00 \\
68^{\prime} 42 \\
66^{\prime} 66 \\
\end{array}$ & $\begin{array}{l}- \\
- \\
6 \\
4\end{array}$ & $\begin{array}{c}- \\
- \\
31^{\prime} 58 \\
33^{\prime} 33\end{array}$ & $\begin{array}{l}40^{\prime} 91 \\
39^{\prime} 39 \\
55^{\prime} 88 \\
37^{\prime} 50\end{array}$ \\
\hline TOTALES. & 53 & 43 & $81^{\prime} 13$ & 10 & $18^{\prime} 87$ & $43^{\prime} 80$ \\
\hline
\end{tabular}

Mientras que en Mayürqa el porcentaje medio de topónimos en beni procedentes del Repartiment es de alrededor de un $18 \%$, en Yäbisa alcanza casi el $44 \%$. Por distritos, Portumany supera en porcentaje a todos los distritos de Mayürqa, Algarb es ligeramente inferior al máximo registrado en la isla mayor (Yartān con el $422^{\prime} 37 \%$ ) y los otros dos distritos de Yäbisa superan ampliamente al resto de los distritos mayurquines.

Este elevado número de topónimos en beni, la inmensa mayoría de los cuales corresponden a alquerías, indican una importantísima organización social de tipo clánico en Yãbisa, muy superior a la registrada en Mayürqa, o al menos reflejan un menor proceso de degradación de esta forma de ocupación de las tierras productivas. Cabe la posibilidad de que Mayürqa, por tratarse de la isla donde reside el poder con mayor nivel de centralización del archipiélago, y estar por tanto sujeta más directamente a los cambios y tensiones políticas del resto de al-Andalus, sufriera modificaciones más substanciales en las formas de cesión y ocupación de las tierras, sobre todo durante el largo período almorávide. La situación que advertimos mediante la documentación catalana es, probablemente, la de un proceso 
diferenciado de degradación del poblamiento de base clánica de ambas islas, siendo este proceso más acelerado para Mayūrqa.

Por otro lado, la constatación de que las alquerías sean el tipo de explotación más generalizado y que al mismo tiempo y en un porcentaje prácticamente idéntico, los topónimos en beni sean alquerías en su inmensa mayoría, refuerza la hipótesis de que el paisaje rural de Yäbisa estaría formado en su estructura básica por grandes explotaciones cuyo proceso productivo estaría organizado en base a los criterios de parentesco propios de las sociedades clánicas.

De entre los topónimos en beni del Memoriale Divisionis, cabe destacar aquellos que hacen referencia a segmentos tribales árabes o magrebíes asentados en tierras ibicencas.

En el distrito de Algarb se han podido identificar los siguientes:

- Caria Benicayz < qarya Beni Qays. La tribu árabe de los Qays 'Aylän llegaron a la Península Ibérica integrando principalmente las divisiones de Damasco y Quinnasrīn, desempeñando un activo papel en las luchas civiles de los primeros tiempos de la dominación musulmana.

- Caria Benipater < qarya Beni Butr (?). Confederación de tribus beréberes a la que pertenecían, según Al-Iștajīī, todos los beréberes llegados a la Península con Tãriq o poco después.

En Benizamid:

- Caria Benifilell < qarya Beni Hiläl. Grupo tribal árabe que hacia la mitad del siglo XI se instala en la parte oriental del Magreb y durante la segunda mitad del siglo XII son deportados a Marruecos procedentes de Tunicia, contribuyendo decisivamente a la arabización lingüística de Marruecos.

En Portumany:

- Caria Benifadale < qarya Bení Fadála. Tribu árabe establecida en la Cirenaica (parte oriental de Libia). Emigraron con los beréberes que vinieron a la Península en el siglo IX.

- Caria Benifilell < qarya Beni Hiläl. Tribu árabe.

- Caria Benimazoch < qarya Bení Marzūq o Merzūq (= los hijos del que ha recibido una riqueza). En el sur de Libia hay un lugar que se llama así y recibe su nombre del de una tribu beréber.

- Caria Beniouara < qarya Benī Hawwära (?). Es una de las cuatro grandes confederaciones de tribus beréberes que según lbn Jaldun emigraron a la Península Ibérica. También podría referirse este topónimo al nombre conocido de familia beréber Benī wārā o wārí.

- Caria Benitroym < qarya Beni Ru'ayn. Tribu árabe yemení del grupo de los Himyaries, del cual había diez nisbas en al-Andalus, según lbn al-Farāḍī. 
- Caria Benisomada < qarya Beni Sümäta. Tribu beréber de la rama de los Nafza. 


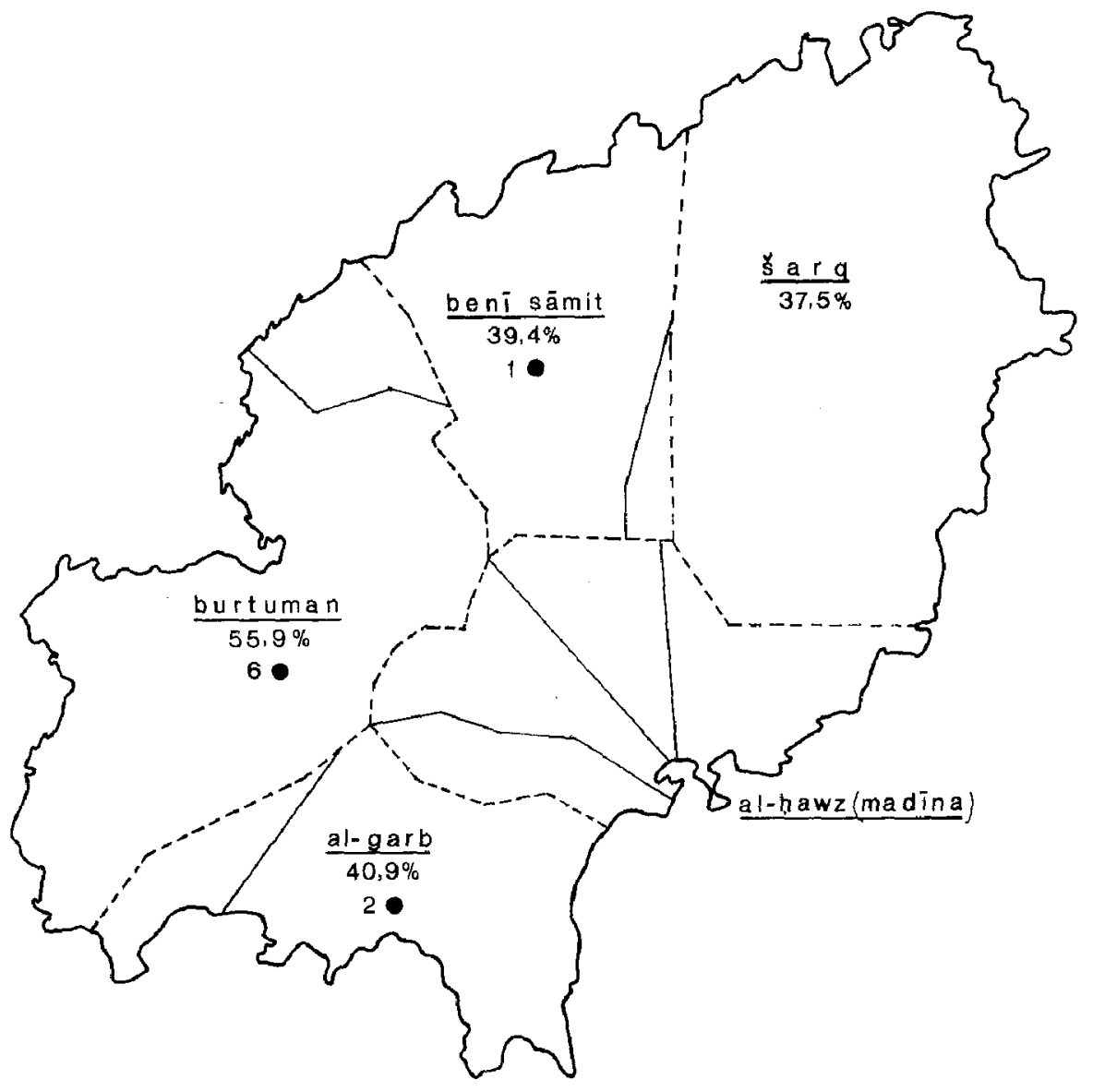

\section{yābisa}

distritos: musulmanes ...... catalanes

(segün j.mari)

$\%$ de toponimia en beni

topónimos tribales en beni — 